\title{
3-Dimensional Approach on Downtown Area to Improve Urban Space Qualities
}

\author{
Fauzan Permana, Endy Yudho Prasetyo \\ Departemen Arsitektur, Fakultas Arsitektur, Desain dan Perencanaan, Institut Teknologi Sepuluh Nopember (ITS) \\ e-mail: endy_yudho_prasetyo@arch.its.ac.id
}

\begin{abstract}
Acting as a Capital of Indonesia, Jakarta has become a core of government, economy, commerce, also cultural hustle of the country. Occupied by 14,464 habitants per km2, its density is twice more than Tokyo, creating a bustling metropolis. The needs of living, commuting and productivity spaces slowly degrading the Green Open Spaces of the city, thus lowering the quality of the city space itself from $32 \%$ in 1965 to $9,8 \%$ in 2017 . Ironically, the active \& dense area of downtown Jakarta where the necessity of green spaces are the highest, are the one where such spaces cannot be found. An intervention therefore needed to refine the city spaces. Implementing 3-dimensional approach on one of the core of Jakarta's downtown area, harmonious with government encouraging a development of walkable city and transit-oriented development, architecture should be able to escalate the quality of space in Jakarta. The design resulted in a simple intervention in the city, that if placed accurately would not only improve the space quality but also integrating areas fractured by other elements of the city.
\end{abstract}

Keywords-3-Dimensional, City, Green Open Space, Urban Space, Quality.

\section{INTRODUCTION}

A $\mathrm{S}$ the capital of Indonesia, Jakarta is the centre for economy, industry, government, culture and commerce. With its inhabitant's density exceeding 14.000 people $/ \mathrm{km} 2$, a lot of spaces are undermined to be used to facilitate commuting automobiles. Yet the $7 \%(42.000 \mathrm{~m} 2)$ of total city's area is already used as roads and planned to be expanded to $12 \%$. The catch is, those soon-to-be-roads spaces are open public spaces such as plazas, parks, pedestrian ways. Eventhough the roads will accomodate the city's commuting needs, in all conscience there are many ways to do it, aside from the simple solution of more roads.

In its people walking index, Indonesia has an average number of 3500 steps per day while Japan has 6000 steps per day, according to Activity Inequality. Jakarta's green open spaces also stuck in a bad number, $9,98 \%$ of supposedly $30 \%$, with diminishing trend of the spaces from $37,2 \%$ in 1965 to $25,85 \%$ in 1985 to $9 \%$ in the 2000 and a slight improvement in 2010 at $9,8 \%$.

Taking considerations from above points, an argument arises, to whom is a city belong to? If it's admittedly for the people, why is developments for a good public and open spaces are not yet intensified? With existing condition of mistreating of of public spaces such as pedestrian way for motorcycle parking and street tenants, among other things that disturbing the flow and circulation, a simple solution of adding more roads only pending the inevitable; more traffic jams. Why is developments for a good public and open spaces are not yet intensified? With existing condition of mistreating of of public spaces such as pedestrian way for motorcycle parking and street tenants, among other things that disturbing the flow and circulation, a simple solution of adding more roads only pending the inevitable; more traffic jams.

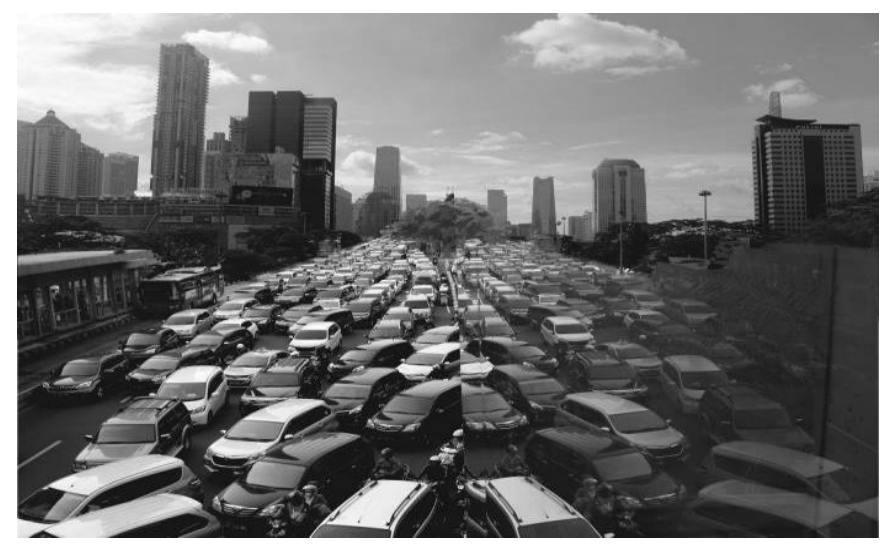

Figure. 1. Density Illustration
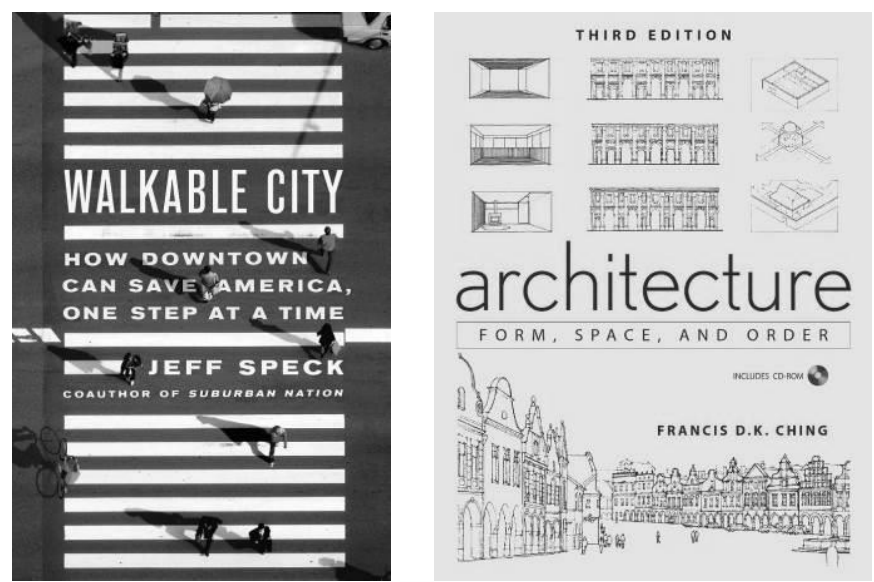

Figure 2. Literatures

According to Francis D. K. Ching in Architecture: Form Space, and Order, plane comes as a result of a line extended in a direction other than its intrinsic direction. In the composition of a visual construction, a plane defines the limits or boundaries of a volume. And while architecture as a visual art deals specifically with the formation of three-dimensional volumes of mass and space, therefore a plane plays as a key element in architectural design [1]. Here we can conclude that plane can construct boundaries in space to the user, as it is made of lines - either a concrete or imaginary ones. When it is imaginary, what are the elements that construct the lines? In The Ecological Approach To Visual Perception, James Gibson stated that visual perception and sense of spaces don't emerge 
from sole interpretation, but through direct interaction between humans and environment. According to Gibson, space and boundaries does not arise from interpretation or formal manifestation, but fundamentally shaped through direct interaction between humans. Where user 'experience' the boundaries itself when they interact and pass through it. With such understanding, we can rethink and recreate the city spaces that are 'occupied' for the automobiles, and with current technology, planes in the $\mathrm{Z}$ axis can be formulated to fulfill the human needs., giving that the space made will be able to fully interact with the users [2].

The initial pivot in approaching the issue is how we reconsider about if built land(roads) are fully utilized 3dimensioanally, then what can be done if there are potensials of innovations that are able to be achieved with today's technology. Also analyzing the general theory of walkability, as the main tool to eliminate the growing numbers of motor vehicles in terms of

design, and translating it from an urban design domain to design aspects of architecture [3]. The site is located at Simpang Semanggi area in Jakarta. As a core area for the city business, commerce and government, Semanggi has a wellbuilt mass transportation, existed and planned around. But, the road interchange itself fracturing the area, keeping each plot of lands seperated with minimum infrastructure for pedestrian. At the centre of the interchange there are some passive-green area that serve minimum purpose, and with the massive circulation of traffic enclosing them, the green spaces are passive \& innaccessible. Around the site are residences, uni, government building and offices with high need of pedestrian circulation around and inside-out of the area. It's downtown, full of place of interests and a network of multiple transjakarta bus stop \& MRT stations(under construction).

The project issue is set out from dense urban area that impacting on the lack of urban space effectiveness. Thus, an active green open space is needed at certain areas to comprehensively accommodate urban activities and performs as a catalyst for the growth of another urban spaces. But paradoxically, at the most dense area which located in the heart of the city, conventional lands are no longer available and inaccessible by humans, in this context, pedestrians. By seeing an area as a 3-dimensional space, design intervention can be developed within the built area, without interrupting and even support - the current activities. Challange of the project is how to create an architectural intervention through the $\mathrm{Z}$ axis to solve city-space problems and to improve the quality of city spaces using 3-dimensional concept as a perspective to see an urban space. And as to cretae the Semanggi Interchange a step towards Jakarta Walkable City. According to Jeff Speck on his speech at TEDx MidAtlantic in 2013, he mentioned The General Theory of Walkability in urban design, which consists of 4 main aspects that has been translated into 3 main concept on architectural design. The first one is Necessity of activities (needs). Here we can conclude that people will walk, or move, when they needed to. By giving a mixed-use program on an architectural object, it could triggers people to move from one facility to another. The object could also be designed by combining circulation and activities, rather than forming deadlock spaces like cul-de-sac to triggers movement. Nearby buildings are also important to serves as attraction for people to move or walk, thus by combining circulation and activities, the proposed object could performs as a space to pass through, not only as a destination. The second one is Safety. On a regular sidewalks or pedestrian way, the risk of people walk by only a couple of centimetres away from a high-speed automobiles cause insecurity towards the street, while this condisition could be worsen if placed alongside the main road. Therefore, platform of the proposed object are designed friendlier than the regular sidewalks, plus it is located above the road. By giving such condition, it is expected that users on the proposed object will feel safer, bigger and invincible against the automobiles below them. And the last one is Interesting and Attractive. By creating an active park in the middle of the interchange, where it was absence from the surrounding area, the object will atract users and gives something new and intresting to the area. Especially when the object is located in the heart of the city with a massive amount of concrete and rigid materials.

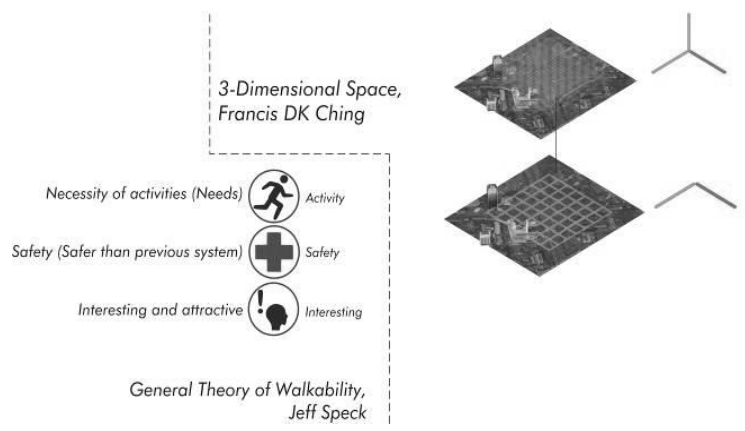

Figure 3. Literature Illustration.

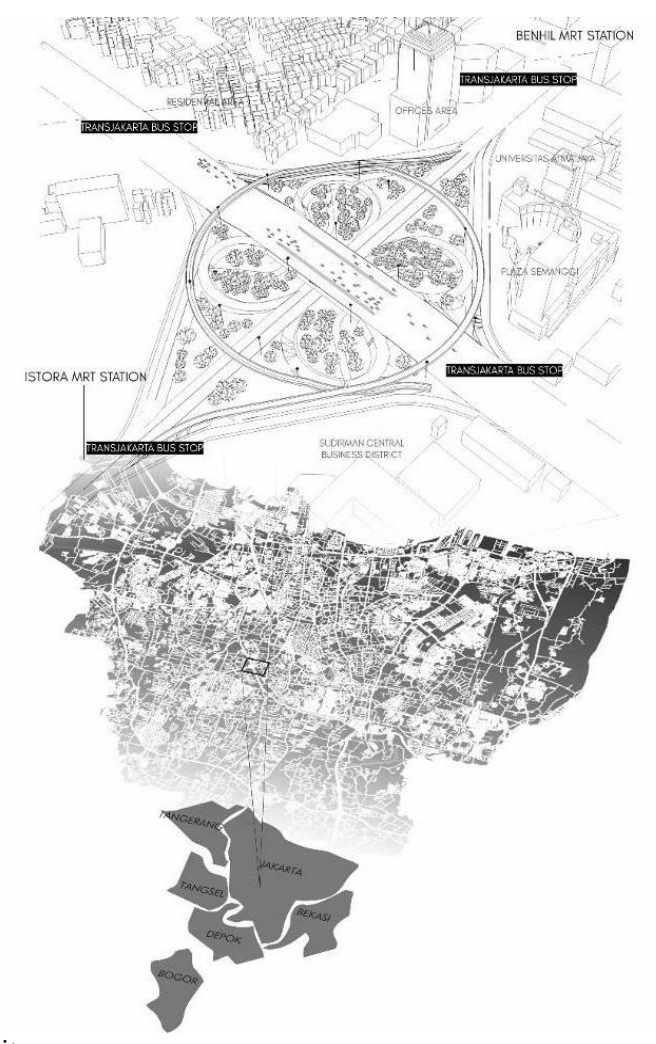

Figure 4. Site. 


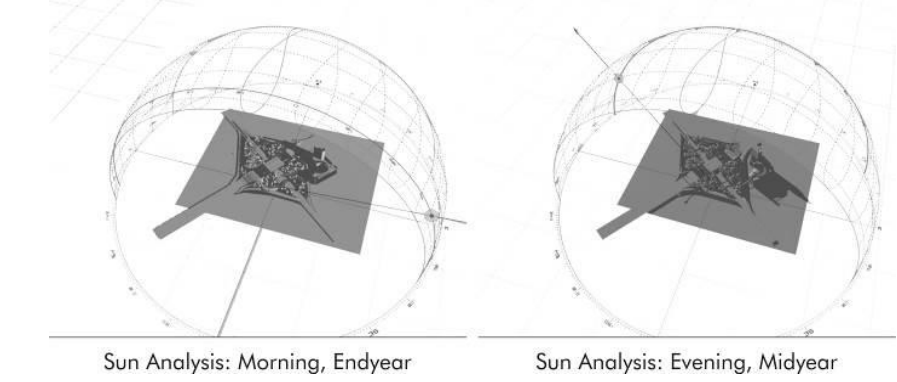

Figure 5. Sun Analysis.

The purposed design aims to be a green public space, afloat in the centre of the city's built area that would act as an anchor that accomodate user's needs, thus improving quality of life.

Design Goals:

The purposed design aims to be a green public space, afloat in the centre of the city's built area that would act as an anchor that accomodate user's needs, thus improving quality of life.

Design Criterias:

1. The design should be built around natural environment, contrary to the solid, massive surrounding area.

2. The design should accommodate public needs

3. The design should be different in a way of how the common typology be designed.

4. The design should have element of walkability, for the sake of diminishing the usage of private vehicles as root problem of the declining quantity and quality of

existing green public spaces.
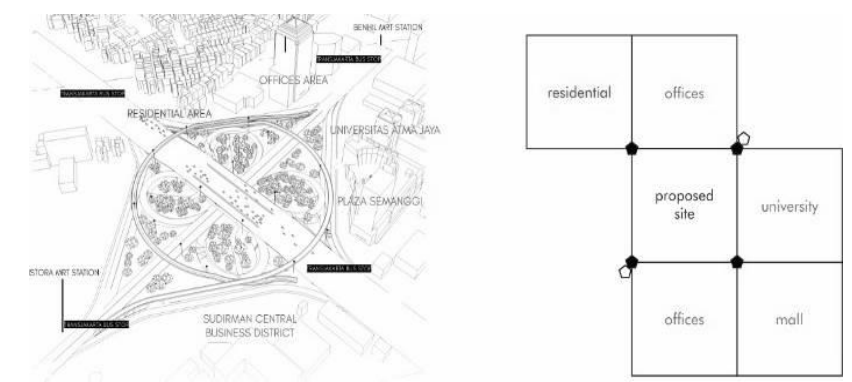

Figure 5. Activity Mapping.
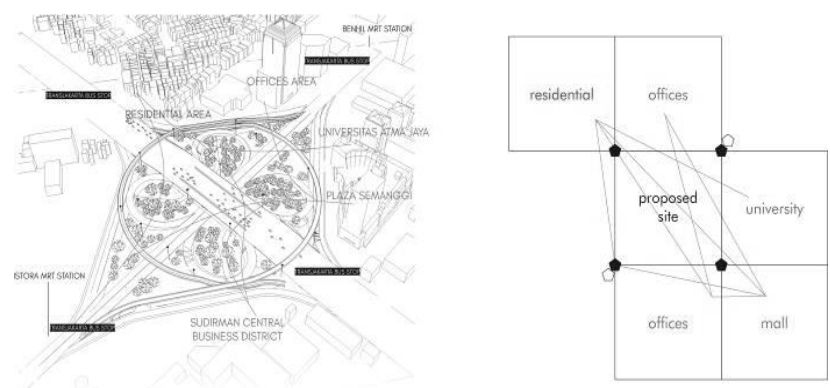

Figure 6. Circulation Mapping.

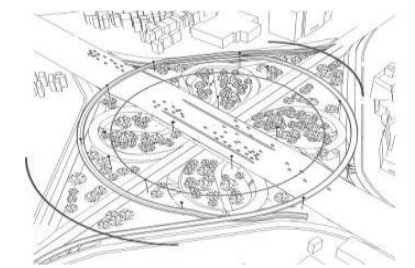

Figure 7. Site Zoning.

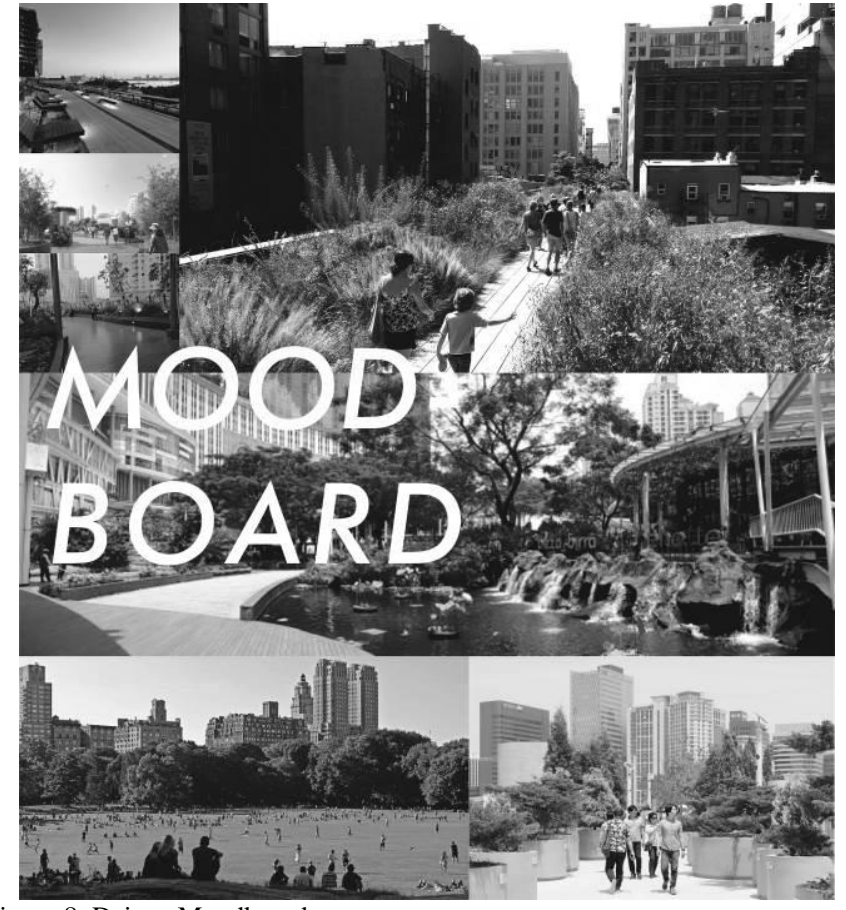

Figure 8. Deisgn Moodboard.

\section{DESIGN METHODS}

Series of hierarchial methods are implemented on the design, to achieve placement, form and programming aspect of the object. In general, there are 3 methods implemented on the proposed project. Intergrated with the previous approach and issue, these 3 methods performs as the technical step to create object's real form and path. The first one is using juxtaposition as a conceptual tools, then using grid and fillet method as the formal tools, and super-imposition as the programmatic tools. Juxtaposition to place the object closely with the radial flyover, creating a visual that will highlight them both. Enhancing the area's identity as the city's icon, harmony between two entities. Grid is used on 2 elevations on the $\mathrm{Z}$ axis of the site to specify in which area in the site are buildable, with the grid planes act as a future-platforms and grid intersections act as points for columns, The elevation's height are decided with safety reasons for both pedestrian and traffic, and also using existing trees acting as a repulsor. The platforms would then be filleted to achieve an organicaestethic cornerless form. In superimposition, two elements of circulation \& activities which determined by different parameters are put on stack together on the site. The circulation is made mostly by external factor of surrounding point of interests, due to the object serving as a place of commuting in the area. The activities, however, are determined by in which area will it has sufficent space for activities, with exsisting trees and vagetations act as repulsor for the platforms.

The activities inside the design would accomodate public needs. As the design would act as an anchor that stitch the fractured urban fabric, in-depth analytics about target user is a neccessity so the object can function as expected. Analyzing from the surrounding area of residential, offices, university and 
shopping mall, the target user would be divided into two types; Residence of Bendungan Hilir and Temporary User in which are college students, workers and city's commuters. Each type are surveyed and enlisted of their needed activities. This way, the object will attract user from both type to the object. And they are able to interact with each other, inducing new activities, communities, and so on. Creating local society or industry that is needed to improve the intangible aspects of urban living.

The activities of the object are a series of public-attractors:

1. Communal Area as main facility of the object, and can be functioned as a space for recreation, a stressreliever, and to accomodate the needs of interacting and as a place for public events.

2. Sports Area, could accommodate the needs of recreation and triggers social interaction between people. This area also provide a space for people living in a dense city life to get some fresh air and be healthier. Albeit located not too far from Gelora Bung Karno Sports Complex, this area is informal and more recreational than those provided in Gelora Bung Karno Sports Complex.

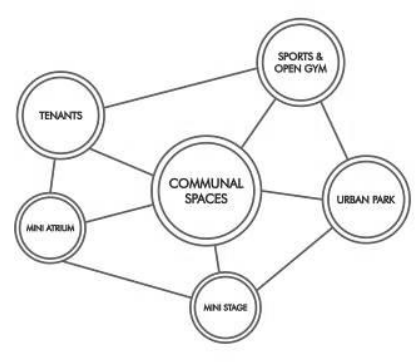

Figure 9. Programs \& User Targets .

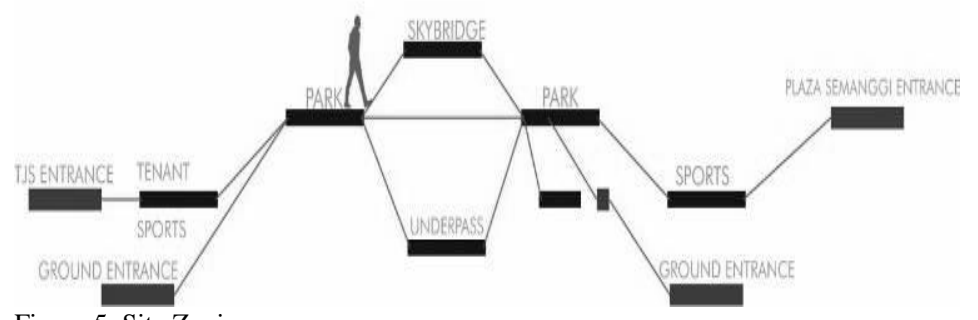

Figure 5. Site Zoning

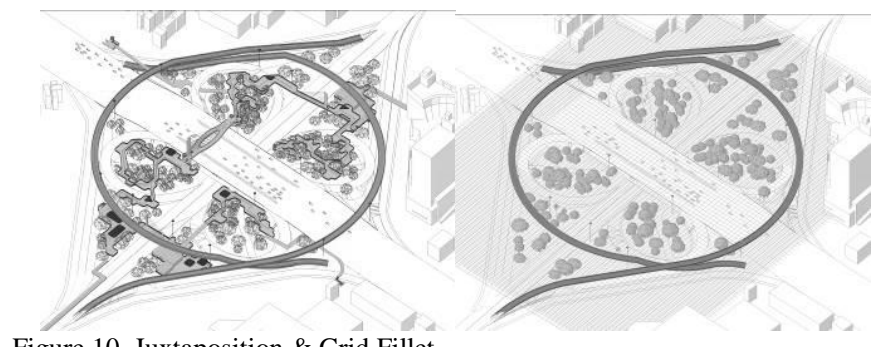

Figure 10. Juxtaposition \& Grid Fillet

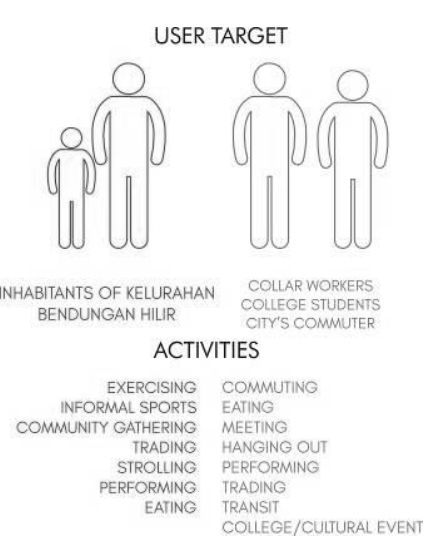

COLLGE/CUITURAL EVENT

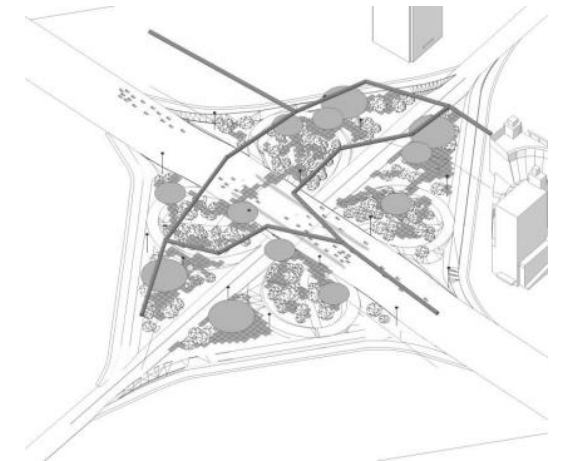

Figure 11. Superimposition Method

3. Urban Park will provide a forest-like area, instead of just a regular park. This facility is needed to create a significantly different atmosphere within the dense city area.

4. Tenant Area performs as a supporting activity which accommodate the needs of people commuting in the area. Includes spaces for street vendors, praying room or musholla, information center, and toilet.

\section{DESIGN RESULT}

With mentioned approaches, methods and contextuality of the site, come up the following concepts:

1. Elevated park, opening access to the object which was obstructed by the interchange at ground level.

2. Grid utilization, to pinpoint locations of platforms and columns and maximizing the use of existing vagetations instead of demolishing them.

3. Radial beam as an aesthethic aspect to people on the ground, tighter bonds for the platform and expanding the range between columns, minimizing their total amount.

4. Concrete structure with visual similiarities with the nearby object(radial flyover) to achieve juxtaposition from ground perspective.

5. WPC flooring for the platforms as a more sustainable substitution for wood.

6. Mesh railing acts as facade,creating semi invinsible look and friendlier facade, instead of creating a massive one that blocks visual to the platform above the ground.

7. Multiple entrances, would accomodate commuters, supports the object as an anchor for the area. One from Transjakarta Bus Stop, one from Plaza Semanggi shopping mall and two from pedetrian way on the ground with stairs and lifts for vertical access.. Each with their respective user targets.

8. Multiple communal space as the main program of th object, to trigger informal activities, inducing communities by accomodating needs from multiple user targets.

9. Outspread bright lighting to prevent misconducts and misbehaving individuals that might happen on the object at night. 
10. Water reuse for the object's facilities to the existing vegetation on the ground as a compensation of some areas on the ground that unable to have rainwater because of the desing above.

The object would also have a sports area, tenant area, many cityscape vistas, mini atrium, vast urban park, surrounded by greenery in the middle of the city's downtown. The object would serve as commuting facilities as well, simplifying pedestrian routes on the area. While the object spans on an area of approximately $15000 \mathrm{~m} 2$, it takes a minimum amount of ground area. The passive green space below is still enjoyable either as visual at normal times or as activities at Car Free Day times, while the floating park is opening access for pedestrian to and around the site while accomodating needs of various users around it.

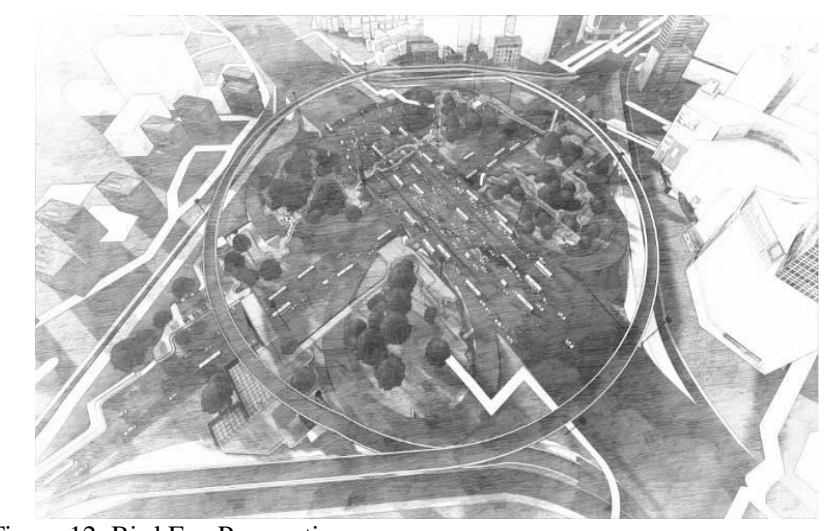

Figure 12. Bird Eye Perspective.

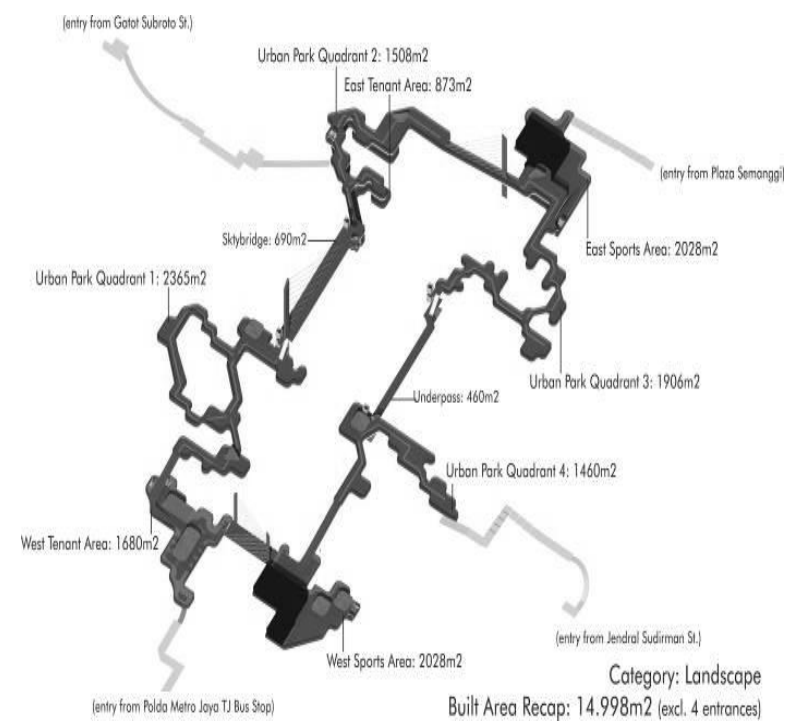

Figure 13. Programs Segmentation on Object.

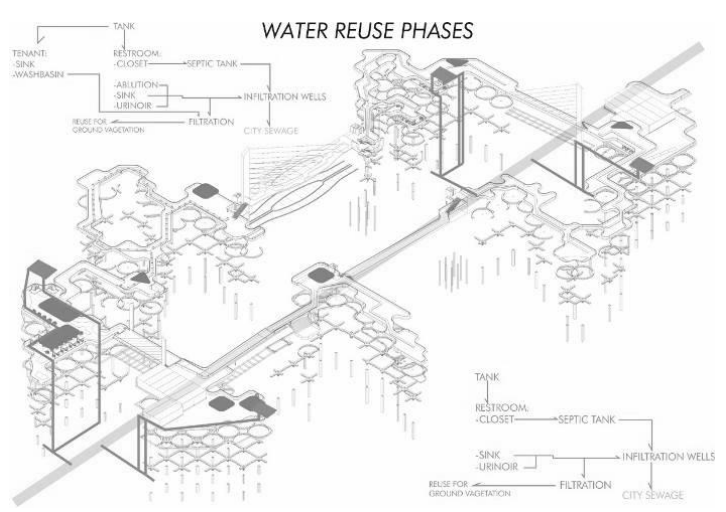

Figure 14. Water Reuse Diagram.

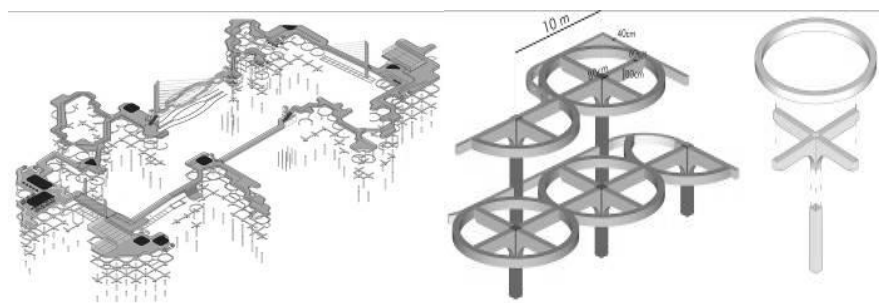

Figure 15. Building's Axonometric \& Structural Details.
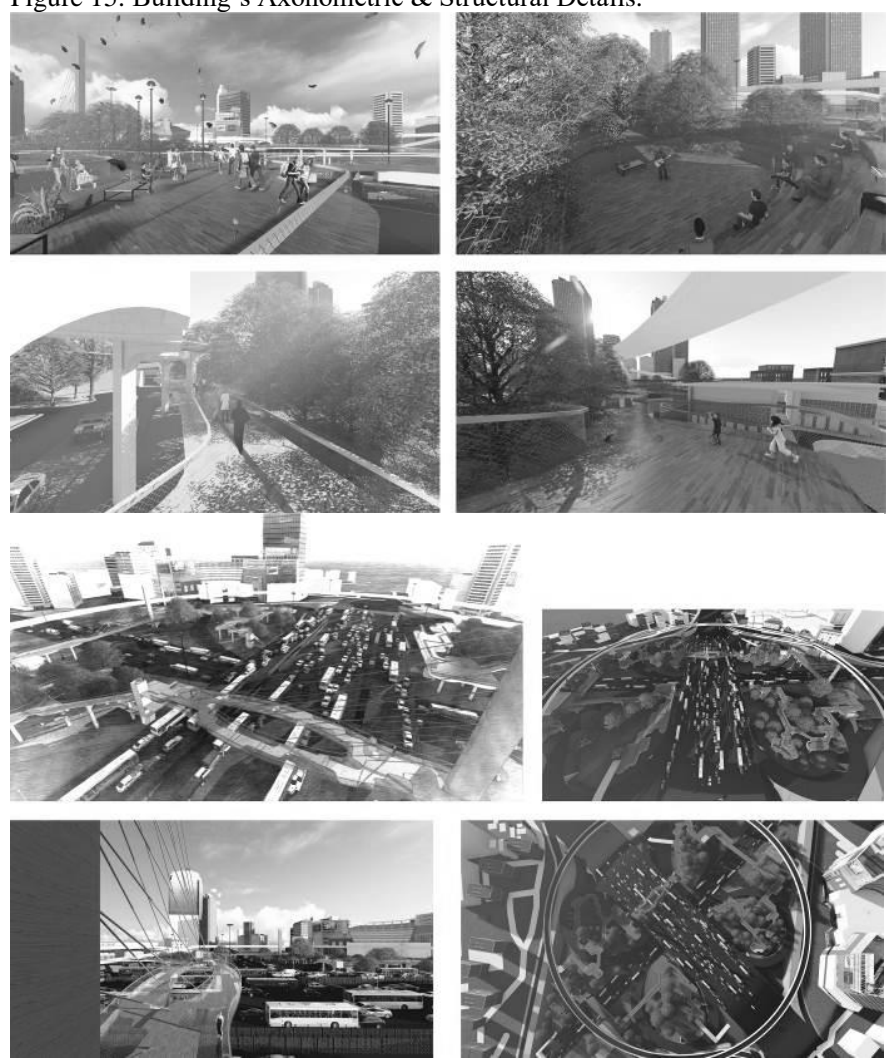

Figure 16. Perspectives 


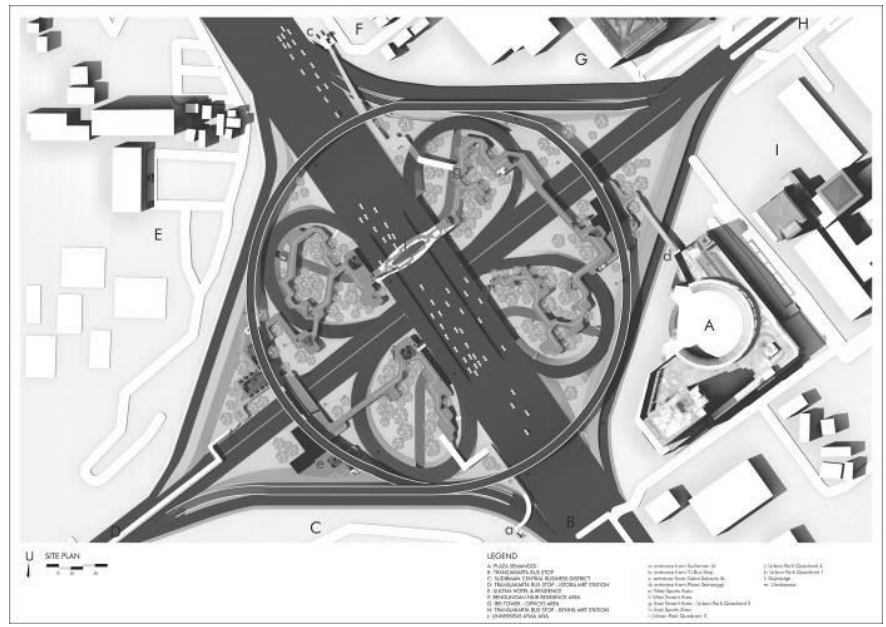

Figure 17. Siteplan

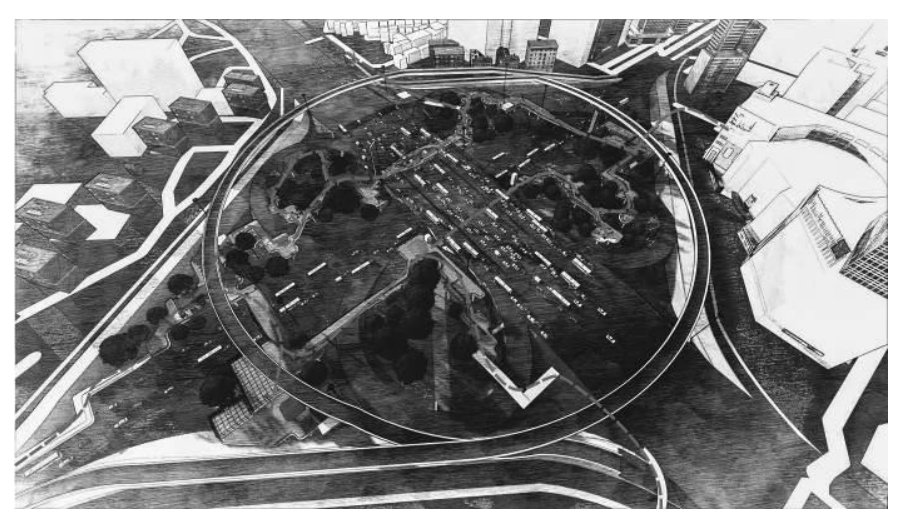

Figure 18. Circulation Diagram.

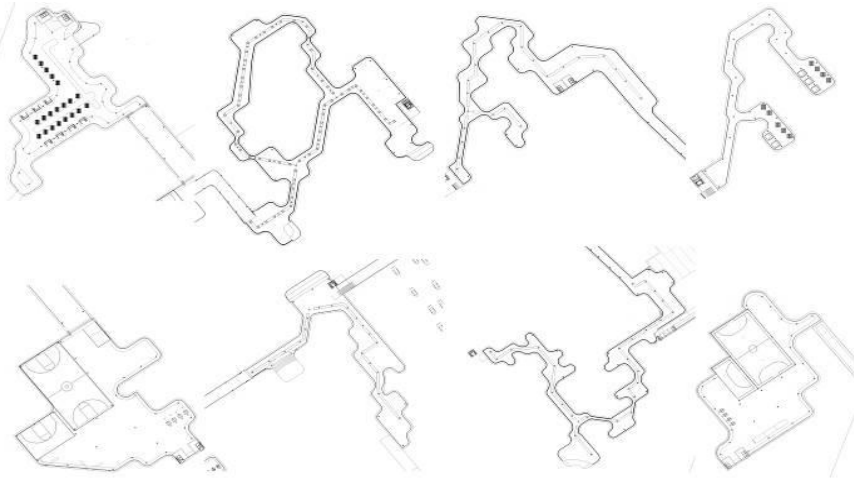

Figure 20. Lighting Plan

\section{CONCLUSION}

While re-using a plot of land in which Semanggi Interchange lies, as an anchor it accomodate user's needs in living and commuting. And as an object at downtown area, it also integrates the surrounding areas, where it was fractured before by connecting point of interests around the site and inducing activities between them. Therefore, the object would improve the quality of public open green space in Jakarta.

\section{REFERENCES}

[1]

F. D. Ching, Architecture : Form, Space, and Order. New York: John Wiley \& Sons Inc, 1995.

[2] J. J. Gibson, The Ecological Approach to Visual Perception. Boston: Massachusetts, 1979.

[3] J. Speck, Walkable City: How Downtown Can Save America, One Step at a Time. New York: Farrar, Straus and Giroux, 2012. 